\title{
Low Expression of CD44 Is an Independent Factor of Poor Prognosis in Ovarian Mucinous Carcinoma
}

\author{
HIROKO MATUURA $^{1}$, MORIKAZU MIYAMOTO ${ }^{1}$, MASASHI TAKANO ${ }^{1}$, \\ HIROAKI SOYAMA ${ }^{1}$, TADASHI AOYAMA ${ }^{1}$, TOMOYUKI YOSHIKAWA ${ }^{1}$, KENTO KATO ${ }^{1}$, \\ TAKAHIRO SAKAMOTO ${ }^{1}$, MIKA KUWAHARA ${ }^{1}$, KAZUKI TAKASAKI $^{1}$, \\ HIROKI ISHIBASHI ${ }^{1}$, HIDEKI IWAHASHI ${ }^{1}$, HITOSHI TSUDA $^{2}$ and KENICHI FURUYA ${ }^{1}$ \\ Departments of ${ }^{1}$ Obstetrics and Gynecology and ${ }^{2}$ Basic Pathology, \\ National Defense Medical College Hospital, Tokorozawa, Japan
}

\begin{abstract}
Aim: To determine whether CD44, which is associated with tumor growth and metastasis, is related to carcinogenesis and prognosis in ovarian mucinous carcinomas (MACs). Materials and Methods: Tissue blocks from 71 patients with benign mucinous ovarian tumors were used in the study: 35 were from patients with borderline mucinous ovarian tumors, and 60 from patients with MACs. Immunochemical analysis was performed to evaluate the expression of CD44 and examine its association with tumorigenesis and survival. Results: Compared to benign tumors, borderline tumors had high CD44 expression levels ( $p=0.047)$. Conversely, MACs had lower expression than borderline tumors $(p=0.032)$. Progression-free and overall survival of patients with MAC with low CD44 expression were worse than those of patients with high expression ( $p=0.04$ and $p=0.02$, respectively). Conclusion: Malignant transformation of mucinous tumors is associated with changes in CD44 expression, with low expression level being a prognostic factor in MAC.
\end{abstract}

The incidence of epithelial ovarian carcinoma (EOC) has been increasing, and the prognosis of patients with advanced-stage disease remains poor despite aggressive treatment $(1,2)$. Ovarian mucinous carcinoma (MAC) accounts for approximately $10 \%$ of histological subtypes of all EOCs (3). In most patients, MAC is diagnosed at an early stage (4). Compared to serous carcinoma, the prognosis of patients with MAC of stage I is favorable (5), but it is worse in those with advanced-stage MAC (6).

Correspondence to: Morikazu Miyamoto, Department of Obstetrics and Gynecology, National Defense Medical College Hospital, 3-2, Namiki, Tokorozawa, Saitama, 359-8513, Japan. E-mail: mmiyamoto@ndmc.ac.jp

Key Words: Ovarian mucinous carcinoma, CD44, prognosis, carcinogenesis.
Furthermore, patients with MAC show a weaker response to platinum-based chemotherapy than individuals with serous carcinomas (7).

MAC develops through an adenoma-carcinoma sequence, originating from cystadenomas and mucinous borderline tumors (8). KRAS mutations represent an early genetic defect in the development of MACs, and their frequency gradually increases as the lesion progresses from benign to borderline and malignant (9).

CD44, a transmembrane protein, is ubiquitous in epithelial and normal tissues and is associated with tumor growth and metastasis (10). At least 10 variants of CD44 are expressed because of alternative splicing of nuclear RNA (11). The roles of CD44 in MAC have not yet been examined.

In this study, we used immunohistochemistry to analyze expression of CD44 in benign, borderline, and malignant mucinous ovarian tumors and investigated whether tumorigenesis of MAC is associated with CD44. Furthermore, we studied the correlation between CD44 and clinicopathological characteristics and evaluated survival according to the level of CD44 in MAC.

\section{Materials and Methods}

Patients and tissue microarray. Tissue blocks from 71 patients with benign mucinous ovarian tumors, 35 patients with borderline mucinous ovarian tumors, and 60 patients with MACs who underwent surgery at the National Defense Medical College between 1984 and 2008 were obtained. We prepared a tissue microarray (TMA) as follows. Cores of $1.5 \mathrm{~mm}$ were punched from donor blocks and inserted into a recipient block. All specimens were cut into 4- $\mu$ m-thick sections. None of the patients had received chemotherapy before surgery. This research was approved by the Ethics Committee of the National Defense Medical College, Tokorozawa, Japan.

Immunochemistry. We used a mouse monoclonal antibody against CD44 (clone 2C5; R\&D Systems, Abingdon, UK). Tissue microarray slides were deparaffinized in xylene, hydrated with 

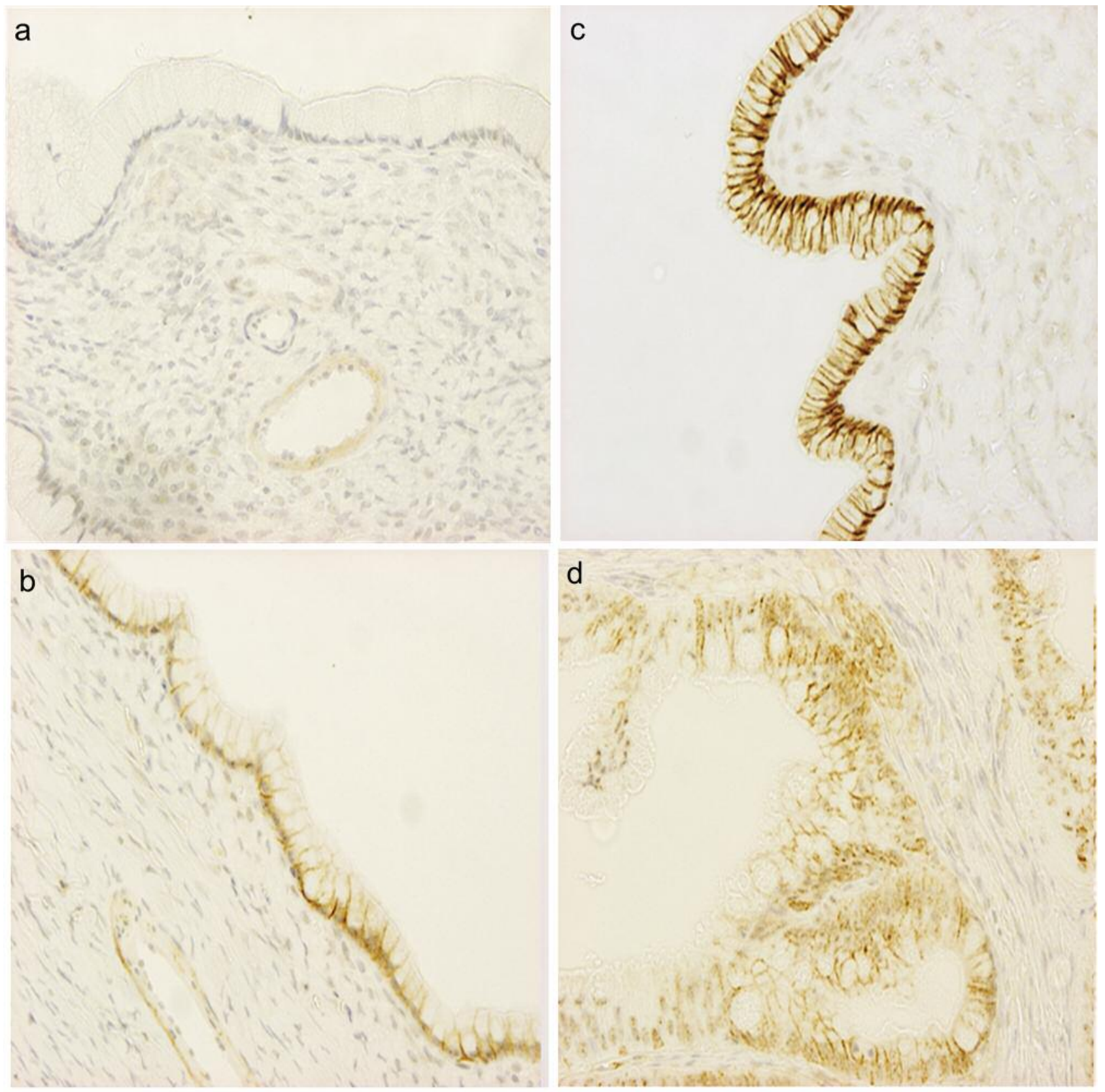

Figure 1. Continued

alcohol, incubated in an autoclave at $121^{\circ} \mathrm{C}$ for 15 minutes in citrate buffer (0.01 M, pH 6.0), and allowed to cool at room temperature. Endogenous peroxidase was blocked by $0.3 \% \mathrm{H}_{2} \mathrm{O}_{2} /$ methanol. The slides were incubated at $4^{\circ} \mathrm{C}$ overnight with primary antibodies, followed by an incubation with the DAKO EnVision+ system horseradish peroxidase labeled polymer with secondary antibodies (DAKO, Carpinteria, CA, USA) for 30 minutes at room temperature. Specific antigen-antibody reactions were visualized with $0.2 \%$ diaminobenzine tetrahydrochloride and hydrogen peroxide, and the slides were counterstained with Mayer hematoxylin. For each antibody, a negative control was prepared without the primary antibody. No significant staining was observed in the negative control sections. Serous ovarian carcinomas are known to be stained with this CD44 antibody (12).

Two investigators blinded to the clinical data independently evaluated and interpreted the results of immunohistochemical staining. The results were interpreted as negative, weak, or strong. Negative and weak cases were then defined as having low expression, whereas those scored as strong were defined as having high expression. 

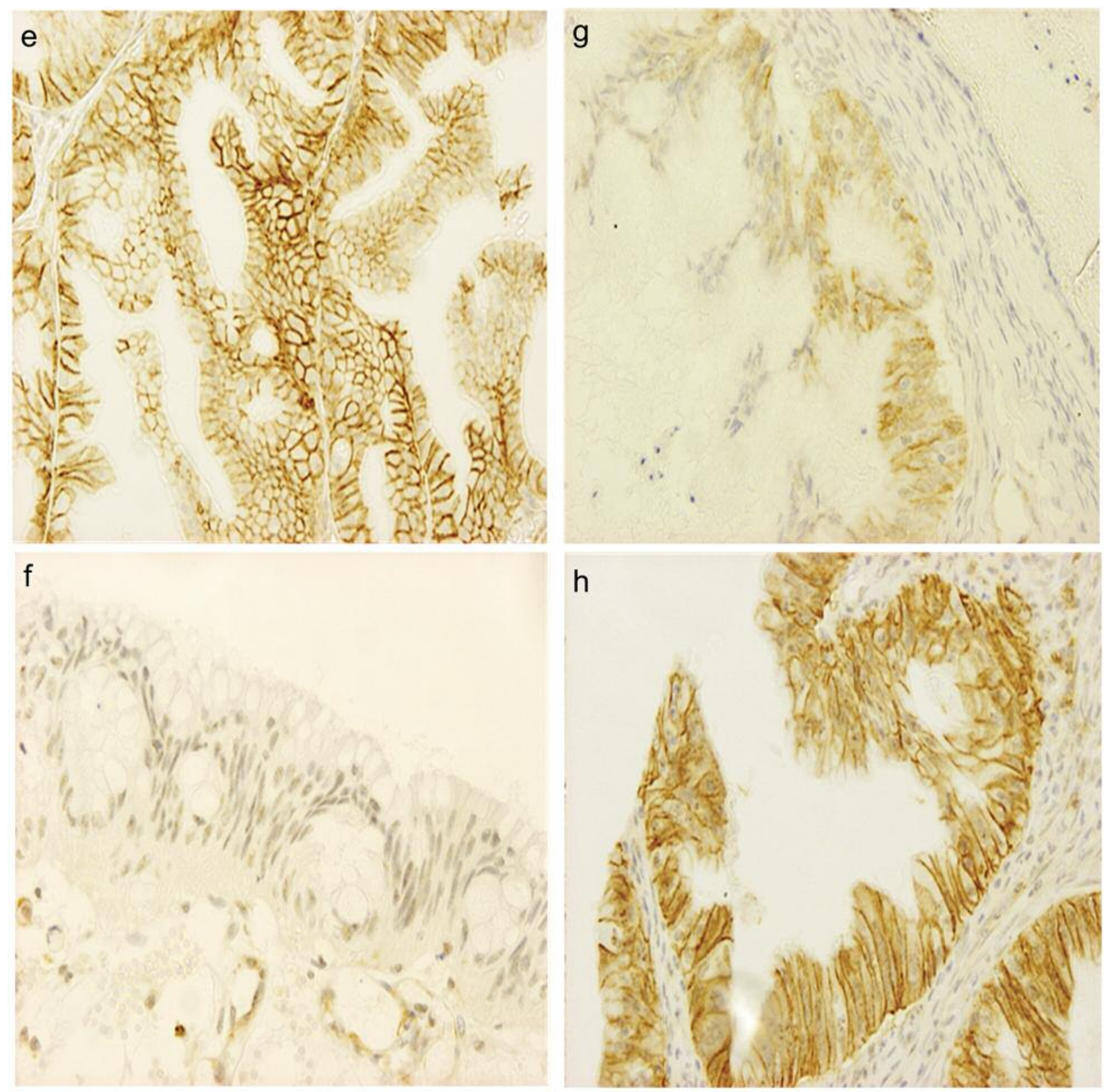

Figure 1. CD44 in ovarian mucinous tumors analyzed by tissue-microarray-based immunohistochemistry. Tissue microarray images corresponding to negative ( $a$ and $f)$, weak ( $b, d$, and $g$ ), and strong ( $c, e$, and $h$ ) CD44 staining. The images show staining in benign mucinous adenomas ( $a$, $b$, and $c)$, borderline mucinous tumors ( $d$ and $e)$, and mucinous carcinomas $(f, g$, and $h)$. Magnification is $\times 20$ in all cases.

Statistical analysis. The Stat View software, version 5.0, (SAS Institution Inc., NC, USA) was used for statistical analysis. Progression-free survival (PFS) was defined as the interval between first treatment and death or the date of disease progression. Overall survival (OS) was defined as the interval between first treatment and death. Staging was performed according to the International Federation of Gynecology and Obstetrics (FIGO) system (13). Performance status was evaluated using the World Health Organization criteria (14). Response rate was estimated based on the Response Evaluation Criteria in Solid Tumors (RECIST) (15). The chi-squared test, Fisher exact test, and Mann-Whitney $U$-test were used to evaluate the expression level of CD44 in several tumor subtypes and associations between expression of CD44 and clinicopathological parameters. PFS and OS curves were generated using the Kaplan-Meier method. Comparisons of survival distributions were made with the log-rank test. A Cox proportional hazards model was used for multivariate analysis of PFS and OS. The level of acceptable statistical significance was set at $p<0.05$. 

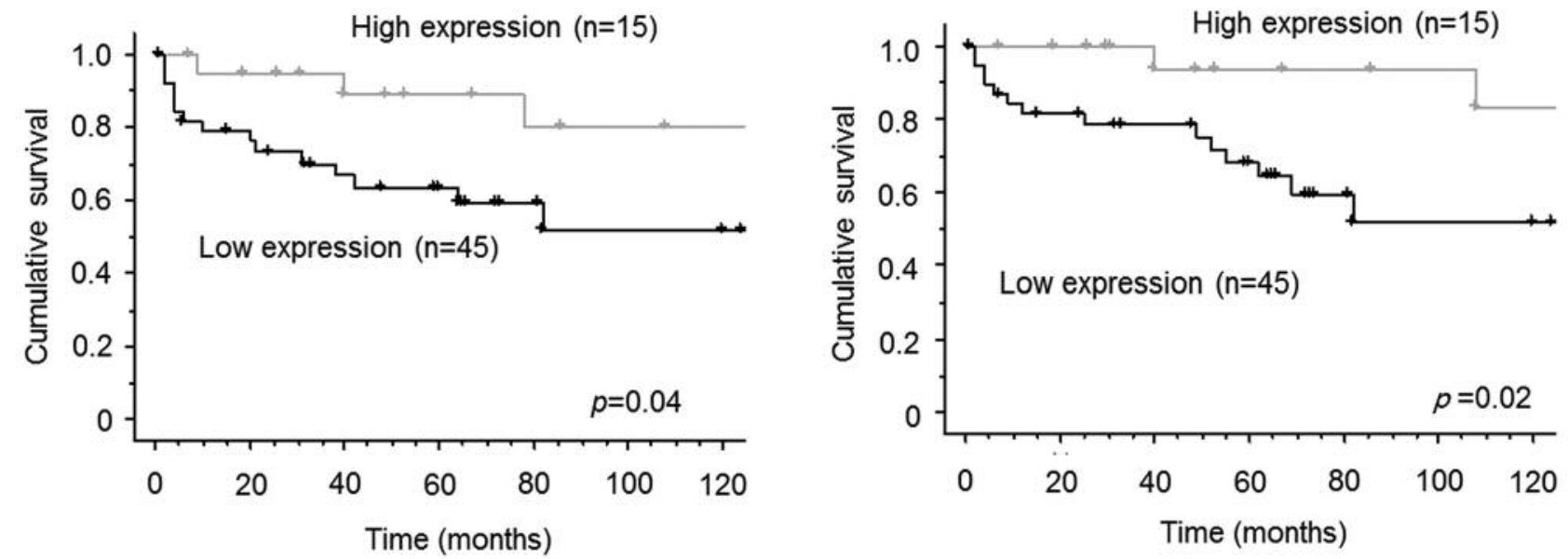

Figure 2. Progression-free (a) and overall $(b)$ survival curves of the 60 patients with ovarian mucinous carcinoma according to expression level of CD44. Low expression: Cases with negative or weak expression; high expression: cases with strong expression.

Table I. Correlation between expression level of CD44 and lesion type.

\begin{tabular}{|c|c|c|c|c|c|}
\hline Tumor type & $\mathrm{N}$ & Negative & Weak & Strong & $p$-Value \\
\hline Mucinous adenoma & 71 & $6(9 \%)$ & $40(56 \%)$ & $25(35 \%)$ & \\
\hline Borderline mucinous tumor & 35 & 0 & $15(43 \%)$ & $20(57 \%)$ & $0.047 *$ \\
\hline Mucinous carcinoma & 60 & $6(10 \%)$ & $33(55 \%)$ & $21(35 \%)$ & $0.03 * *$ \\
\hline
\end{tabular}

*Compared to mucinous adenomas; **compared to borderline mucinous tumors.

\section{Results}

Representative images of immunostaining are shown in Figure 1. Table I shows expression levels of CD44 in benign, borderline, and malignant mucinous tumors. Compared with benign mucinous tumors, there were significantly more cases of borderline mucinous tumor $(p=0.047)$ with strong expression. Conversely, there were fewer cases of MAC with strong expression compared with borderline tumors $(p=0.032)$.

Table II shows the correlations between CD44 expression levels and clinicopathological features in 60 patients with MAC. There were no statistically significant differences in age, performance status, stage, presence of residual tumors, and presence of chemotherapy between groups with high and low expression of CD44. PFS and OS of patients with MACs with low expression of CD44 were worse than those of patients with high expression (Figure 2a: PFS, $p=0.04$; Figure 2b: OS, $p=0.02$ ). Table III shows the results of multivariate analysis of 60 patients with MACs. Low expression of CD44, presence of residual tumors, and performance status were prognostic factors of PFS. Similarly, low expression of CD44, performance status, and presence of residual tumors were prognostic factors of OS.
Table II. Characteristics of 60 cases with mucinous ovarian carcinomas.

\begin{tabular}{|c|c|c|c|}
\hline \multirow[b]{2}{*}{ Variable } & \multicolumn{2}{|c|}{ CD44 expression } & \multirow[b]{2}{*}{$p$-Valu } \\
\hline & Low $(n=39)$ & $\operatorname{High}(\mathrm{n}=21)$ & \\
\hline \multicolumn{4}{|l|}{ Age, years } \\
\hline Median (range) & $53(19-78)$ & $43(18-82)$ & 0.25 \\
\hline \multicolumn{4}{|c|}{ Performance status, n (\%) } \\
\hline 0 & $36(92 \%)$ & $19(90 \%)$ & 0.99 \\
\hline 1 & $3(8 \%)$ & $2(10 \%)$ & \\
\hline \multicolumn{4}{|l|}{ Stage, n (\%) } \\
\hline I/II & $29(74 \%)$ & $17(81 \%)$ & 0.54 \\
\hline III/IV & $10(26 \%)$ & $4(19 \%)$ & \\
\hline \multicolumn{4}{|c|}{ Residual tumor, n (\%) } \\
\hline None & $29(75 \%)$ & $17(81 \%)$ & 0.75 \\
\hline$<1 \mathrm{~cm}$ & $4(10 \%)$ & 0 & \\
\hline$\geq 1 \mathrm{~cm}$ & $6(15 \%)$ & $4(19 \%)$ & \\
\hline \multicolumn{4}{|c|}{ Chemotherapy, n (\%) } \\
\hline Platinum-based & $36(92 \%)$ & $16(76 \%)$ & 0.11 \\
\hline None & $3(8 \%)$ & $5(24 \%)$ & \\
\hline \multicolumn{4}{|c|}{ Response rate, n (\%) } \\
\hline $\mathrm{CR} / \mathrm{PR}$ & $5(50 \%)$ & $2(50 \%)$ & 0.99 \\
\hline $\mathrm{SD} / \mathrm{PD}$ & $5(50 \%)$ & $2(50 \%)$ & \\
\hline
\end{tabular}

Low expression: Cases with negative or weak expression; high expression: cases with strong expression; CR/PR: complete/partial response; $\mathrm{SD} / \mathrm{PD}$ : stable/progressive disease. 
Table III. Multivariate analysis of progression-free and overall survival in 60 patients with mucinous ovarian carcinomas.

\begin{tabular}{|c|c|c|c|c|c|c|c|}
\hline \multirow[b]{2}{*}{ Variable } & \multirow[b]{2}{*}{ Comparison } & \multicolumn{3}{|c|}{ Progression-free survival } & \multicolumn{3}{|c|}{ Overall survival } \\
\hline & & Hazard ratio & $95 \% \mathrm{CI}$ & $p$-Value & Hazard ratio & $95 \% \mathrm{CI}$ & $p$-Value \\
\hline Age & $<55 v s . \geq 55$ years & 0.51 & $(0.17-1.51)$ & 0.22 & 0.48 & $(0.13-1.76)$ & 0.27 \\
\hline Performance status & 1 vs. 0 & 6.65 & $(1.55-28.5)$ & 0.01 & 13.9 & $(2.78-69.1)$ & $<0.01$ \\
\hline FIGO stage & I/II vs. III/IV & 0.35 & $(0.03-1.29)$ & 0.11 & 0.23 & $(0.05-1.01)$ & 0.051 \\
\hline Residual tumor & $\geq 1 \mathrm{~cm} v s .<1 \mathrm{~cm}$ & 4.61 & $(1.10-19.2)$ & 0.04 & 8.77 & $(1.65-45.5)$ & 0.01 \\
\hline CD44 & Low $v s$. high expression & 8.54 & $(2.01-37.0)$ & $<0.01$ & 26.3 & $(3.51-200)$ & $<0.01$ \\
\hline
\end{tabular}

CI: Confidence interval; FIGO: Federation of Gynecology and Obstetrics.

\section{Discussion}

Most studies dedicated to the prognostic role of CD44 expression level in ovarian carcinomas included either all histological subtypes $(12,16-20)$ or only serous carcinomas (21). There have been no reports focusing on ovarian mucinous carcinomas. To our knowledge, this study is the first to investigate the role of CD44 in tumorigenesis and prognosis of MACs.

Generally, CD44 plays the main role in many cell-cell and cell-matrix interactions, including cell adhesion and migration (22). CD44 was found to be up-regulated during the development of ovarian carcinomas but subsequently down-regulated during their progression (16). Our study showed a higher rate of strong CD44 expression in borderline mucinous tumors than in benign mucinous tumors, whereas the rate of strong CD44 expression in MACs was lower than that in borderline mucinous tumors. These results suggest that CD44 expression increases in the process of malignant transformation and decreases during the invasive process corresponding to the development of MAC via an adenoma-carcinoma sequence (3), which is consistent with a previous report (16).

Most studies identified an association between low CD44 expression and advanced cancer stage $(12,16,17)$. The opinions about whether CD44 expression is related to prognosis are divided $(12,16-21)$. A study of a large number $(\mathrm{N}=307)$ of ovarian carcinomas demonstrated low expression of CD44 to be a factor of poor prognosis (12). Nevertheless, a definitive conclusion has not been reached. We found no relation between CD44 expression level and FIGO stage. This result, however, is somewhat weakened by the small sample size. Nonetheless, it is important that low expression of CD44 in MAC was able to predict poor prognosis. Although most MACs are diagnosed at stage I (6), such patients, despite incomplete surgery, might include those with up-staged disease. Recently, a retrospective analysis suggested that fertility-sparing surgery is feasible in patients with stage I MACs (23). Because metastasis may be ongoing in pw stage I MAC with low CD44 expression, we should not perform fertilitysparing surgery in such cases.

In conclusion, malignant transformation and invasion by mucinous tumors were associated with CD44 expression level, and low CD44 expression was an independent prognostic factor in patients with MACs. Future studies should develop treatment strategies according to the level of CD44 expression.

\section{Conflicts of Interest}

The Authors declare no potential conflicts of interest in regard to this study.

\section{Acknowledgements}

None.

\section{References}

1 Baldwin LA, Huang B, Miller RW, Tucker T, Goodrich ST, Podzielinski I, DeSimone CP, Ueland FR, van Nagell JR and Seamon LG: Ten-year relative survival for epithelial ovarian cancer. Obstet Gynecol 120: 612-618, 2012.

2 Cannistra SA: Cancer of the ovary. N Engl J Med 351: 25192529, 2004

3 McGuire V, Jesser CA and Whittemore AS: Survival among U.S. women with invasive epithelial ovarian cancer. Gynecol Oncol 84: 399-403, 2002.

4 Malkasian GD Jr, Melton LJ 3rd, O'Brien PC and Greene MH: Prognostic significance of histologic classification and grading of epithelial malignancies of the ovary. Am J Obstet Gynecol 149: 274-284, 1984.

5 Vergote I, De Brabanter J, Fyles A, Bertelsen K, Einhorn N, Sevelda P, Gore ME, Kaern J, Verrelst H, Sjövall K, Timmerman D, Vandewalle J, Van Gramberen M and Tropé CG: Prognostic importance of degree of differentiation and cyst rupture in stage I invasive epithelial ovarian carcinoma. Lancet 357: 176-182, 2001.

6 Winter WE 3rd, Maxwell GL, Tian C, Carlson JW, Ozols RF, Rose PG, Markman M, Armstrong DK, Muggia F and McGuire WP: Gynecologic Oncology Group Study: Prognostic factors for stage III epithelial ovarian cancer: a Gynecologic Oncology Group Study. J Clin Oncol 25: 3621-3627, 2007. 
7 Shimada M, Kigawa J, Ohishi Y, Yasuda M, Suzuki M, Hiura M, Nishimura R, Tabata $T$, Sugiyama $T$ and Kaku T: Clinicopathological characteristics of mucinous adenocarcinoma of the ovary. Gynecol Oncol 113: 331-334, 2009.

8 Puls LE, Powell DE, DePriest PD, Gallion HH, Hunter JE, Kryscio RJ and van Nagell JR Jr.: Transition from benign to malignant epithelium in mucinous and serous ovarian cystadenocarcinoma. Gynecol Oncol 47: 53-57, 1992.

9 Cuatrecasas M, Villanueva A, Matias-Guiu X and Prat J: K-ras mutations in mucinous ovarian tumors: a clinicopathologic and molecular study of 95 cases. Cancer 79: 1581-1586, 1997.

10 Ponta H, Wainwright D and Herrlich P: The CD44 protein family. Int J Biochem Cell Biol 30: 299-305, 1998.

11 Screaton GR, Bell MV, Bell JI and Jackson DG: The identification of a new alternative exon with highly restricted tissue expression in transcripts encoding the mouse Pgp-1 (CD44) homing receptor. Comparison of all 10 variable exons between mouse, human and rat. J Biol Chem 268: 12235-12238, 1993.

12 Sillanpää S, Anttila MA, Voutilainen K, Tammi RH, Tammi MI, Saarikoski SV and Kosma VM: CD44 expression indicates favorable prognosis in epithelial ovarian cancer. Clin Cancer Res 9: 5318-5324, 2003.

13 Prat J: FIGO Committee on Gynecologic Oncology: Staging classification for cancer of the ovary, fallopian tube and peritoneum. Int J Gynaecol Obstet 124: 1-5, 2014.

14 Oken MM, Creech RH, Tormey DC, Horton J, Davis TE, McFadden ET and Carbone PP: Toxicity and response criteria of the Eastern Cooperative Oncology Group. Am J Clin Oncol 5: 649-55, 1982.

15 Therasse P, Arbuck SG, Eisenhauer EA, Wanders J, Kaplan RS, Rubinstein L, Verweij J, Van Glabbeke M, van Oosterom AT, Christian MC and Gwyther SG: New guidelines to evaluate the response to treatment in solid tumors. European Organization for Research and Treatment of Cancer, National Cancer Institute of the United States, National Cancer Institute of Canada. J Natl Cancer Inst 92: 205-216, 2000.
16 Saegusa M, Machida D, Hashimura M and Okayasu I: CD44 expression in benign, premalignant and malignant ovarian neoplasms: relation to tumour development and progression. J. Pathol 189: 326-337, 1999.

17 Ross JS, Sheehan CE, William SS, Malfetano JH, Szyfelbein WM and Kallakury BV: Decreased CD44 standard form expression correlates with prognostic variables in ovarian carcinomas. Am J Clin Pathol 116: 122-128, 2001.

18 Yeo TK, Nagy JA, Yeo KT, Dvorak HF and Toole BP: Increased hyaluronan at sites of attachment to mesentery by CD44-positive mouse ovarian and breast tumor cells. Am J Pathol 148: 17331740, 1996.

19 Kayastha S, Freedman AN, Piver MS, Mukkamalla J, RomeroGuittierez M and Werness BA: Expression of the hyaluronan receptor, CD44s, in epithelial ovarian cancer is an independent predictor of survival. Clin Cancer Res 5: 1073-1076, 1999.

20 Cannistra SA, Abu-Jawdeh G and Niloff J, Strobel T, Swanson $\mathrm{L}$ andersen $\mathrm{J}$ and Ottensmeier C: CD44 variant expression is a common feature of epithelial ovarian cancer: lack of association with standard prognostic factors. J Clin Oncol 13: 1912-1921, 1995.

21 Berner HS, Davidson B, Berner A, Risberg B, Kristensen GB, Trope CG, Van PG and Nesland JM: Expression of CD44 in effusions of patients diagnosed with serous ovarian carcinoma: diagnostic and prognostic implications. Clin Exp Metastasis 18: 197-202, 2000.

22 Lesley J, Hyman R and Kincade PW: CD44 and its interaction with extracellular matrix. Adv Immunol 54: 271-335, 1993.

23 Kajiyama H, Shibata K, Mizuno M, Nawa A, Mizuno K, Matsuzawa K, Kawai M, Hosono S, Nagasaka T and Kikkawa F: Fertility-sparing surgery in young women with mucinous adenocarcinoma of the ovary. Gynecol Oncol 122: 334-338, 2011.

Received October 23, 2017

Revised November 9, 2017

Accepted November 10, 2017 